\title{
Management of Devolved Health Services and Healthcare Service Delivery in Arid and Semi-Arid Lands in Kenya
}

\author{
Abdihafid Abdullahi Yarow ${ }^{1}$, Shadrack Jirma ${ }^{1} \&$ Elijah Siringi ${ }^{1}$ \\ ${ }^{1}$ School of Management and leadership, Management University of Africa, Nairobi, Kenya \\ Correspondence: Abdihafid Abdullahi Yarow, School of Management and leadership, Management University of \\ Africa, Nairobi, Kenya. E-mail: abdi78@gmail.com
}

Received: July 9, 2019

Accepted: August 15, 2019

Online Published: September 5, 2019

doi:10.5539/ijbm.v14n10p21

URL: https://doi.org/10.5539/ijbm.v14n10p21

\begin{abstract}
The 2010 Constitution provides a legal framework that guarantees an all-inclusive rights-based approach to health service delivery to Kenyans. It provides that Kenyans are entitled to the highest attainable standards of health, which includes the right to healthcare services including reproductive health care (Article 43). The purpose of this study was to investigate the the extent to which management of devolved health services influence health-care service delivery in Arid and Semi-Arid Lands in Kenya. This study was guided by fiscal decentralization theory and theory of performance improvement, as well as sequential theory of decentralization. This study used a triangulation of both positivism and phenomenology. The population under this study constitute the Sub-Counties in ASAL in Kenya with a sample size of 89 Sub-Counties being sampled and 3 patients from each of the 89 sampled sub counties. This study found that, since the onset of devolution, there has been introduction of more healthcare facilities at counties in ASAL resulting with sub-county leaderships have been largely considering the opinions raised by the residents while implementing health services decisions. Management of devolved health services, healthcare has greatly made health facilities and services more accessible to residents compared to before with the previous five years recording great improvement in the quality of the health services at county health centers. The national government should therefore consider increasing financial resources to counties, which would eventually enhance health manpower for better service delivery. This study therefore recommends that the hospitals management should come up with strategies that can help improve financial resources to fund facilities improvement.
\end{abstract}

Keywords: devolution, health services, healthcare service delivery

\section{Introduction}

Devolution is one of the administrative decentralization categories and involves legal transfer of authority and administrative powers to political units like County governments. It is also the strongest form of governance decentralization (Olatona \& Olomola, 2015). Devolution involves a rescaling of responsibilities or powers from the national to the regional political organization (Lobao et al., 2009). This underlines the need for researchers to be specific about precisely what is being rescaled or devolved in particular contests. In Kenya, management of devolved health-care services has left the national government with the responsibility of managing the referral hospitals and developing national policy while county governments are entrusted with all functions related to health-care delivery.

The main aim of devolving healthcare services is to improve effectiveness and efficiency of health service provision through decision making re-allocation. Devolving of the healthcare system may have a significant influence on availability and adequacy of financial resources, human resource, health facilities, medical equipment and supplies in healthcare facilities, which may subsequently influence the quality of childbirth services. The county structures were in a rush to consolidate their power and hold over the lucrative health sector. As a result, transition from the national to county government has been marred by inconsistency, poor staffing of the system, management challenges and lack of coordination between the national and county governments (Ministry of Devolution and National Planning, 2015). Management of devolved health-care services also presents institutional and resource allocation utilization challenges that must be dealt with to ensure effective and sustainable health care service delivery in the counties.

According to Lowe (2012), health care services provisions in the devolved system of governance refers to the 
various processes undertaken by sub-national governments through which inputs like; finances, human resources, equipment, medical drugs and other essential supplies are amalgamated to facilitate the delivery of health interventions to the populace. Jooste and Fourie (2009) observes that it is the lack of one or several of these inputs that influences the provision of healthcare in the devolved even at lowest level; primary care. Mongkol (2011) reported on challenges of distribution of human resources for health that did adversely influence the implementation of health care projects by regional governments for the provision of health services in Chile.

Across the globe, experiences in devolving the health function are both good and not so good. Some countries and regions have succeeded in rolling out devolution to improve healthcare; others have failed. In the Philippines, for instance, devolution relatively increased resource allocation, facilitated greater citizen participation in addressing unique health needs and bolstered decision-making process at the local levels (Ansari et al., 2011). In the UK, devolution has allowed four divergent health systems (in Britain, Scotland, Wales and Northern Ireland) responsive to the uniqueness of their health demands to coexist (Woods, 2004). Elsewhere, in Pakistan, District Administrators failed to prioritize health hence limiting resource allocations. Health care delivery thus stagnated despite devolution (Batley, 2004).

In a study on the influence of devolution on the healthcare system in Pakistan, Shiraz et al. (2013) found that devolution had a positive influence on monitoring and supervision of healthcare service delivery and led to a greater financial autonomy to prioritize according to the needs. However, the study found that there were key challenges facing service delivery after devolution, which include inadequate human capacity, poor governance, inadequate medical supplies, late release of funds and lack of healthcare facilities like laboratories, incubators and adequate maternity wards. Management of devolved health care also improves citizen participation and client voice, and promotes a better fit between services, local conditions and recipient demands.

In Africa, Nannyonjo and Oko (2013) reported that poor distribution of Human Resource for Health (HRH) and in particular doctors who were fewer than nurses did pose challenges to county governments in their quest to implement health care projects and provide health care services especially in rural Uganda. Kenya's healthcare system was first decentralised in the early 1980s using the District Focus for Rural Development (DFRD) approach where the district was the basic unit of public service delivery. It aided the central government in budgeting, planning, organising, and implementing essential programmes (Chitere \& Ireri, 2004). A case study in Tanzania found that decentralized recruitment resulted in a more realistic distribution of staff compared to centralized recruitment, where the posting of staff was earlier less responsive to the specific needs of the districts, although Government of Tanzania later opted for a recentralization of recruitment procedures. Rwandan devolution reform in the health sector has been a major success mainly because of its positive influence in efficiency in service delivery and reduction in child and maternal mortality (Nuguid, 2011).

In Kenya, management of devolved healthcare in Kenya is anchored on the Kenyan Constitution 2010 and it underscores the right of every person to receive the highest attainable standard of health. The underlying assumption of devolving the healthcare system is well stated by Murkomen (2012), a devolution expert, who says that the health system in Kenya was devolved in order to promote access to quality, efficient and equitable health services throughout the country and to address the problems of bureaucracy especially in procurement. With the advent of devolution, the public health sector went into a spin following a protracted stand-off between the national and county governments and the industry players over the management of health services. Notably, while other health functions have been devolved to the counties, the national government remains in charge of training, welfare and promotions, yet the major bone of contention has been remuneration, which doctors and nurses claim county governments are ill-equipped to handle. For the better part of the year 2016, we witnessed a number of strikes by nurses and doctors, which compromised the quality of service.

Sihanya (2013) posits that devolution can make the actions of local officials more transparent and provide a check on corruption, appointments based on family ties or other connections and other poor practices. However, this assumes that there is an active local political system, news outlets which are themselves not part of these webs of influence and that people will be prepared to blow the whistle where they see problems and that they will be listened to. External audit and review and the opportunity for issues of this sort to be escalated may be required. Devolving responsibilities does not only impact on those organisations or regions where responsibilities are devolved to, it also impacts on the organisation - typically Ministry of Health - that is devolving its authority. Good governance should clearly spell out what policies the Ministry of Health would still be responsible for in a devolved health system. Examples of these are quality regulations and education and training of doctosrs. The role of a Ministry is therefore likely to be one of 'stewardship' and 'guidance' instead of 'own and control' in a devolved system. 
This paper was guided by the following null hypothesis hypothesis:

HO: There is no significant relationship between management of devolved health services and healthcare service delivery in Arid and Semi-Arid Lands, Kenya.

\section{Method}

This section explained the methodology to be applied in this research.

\subsection{Research Philosophy and Design}

This study used a triangulation of both positivism and phenomenology using questionnaire-based surveys, observation, and secondary sources, which further makes the approach best suited for this study. Thus, the notion of open-ended questions and conversational inquiry allowed research participants to talk about the topic in their own words, free of the constraints imposed by fixed-response questions that are generally seen in quantitative methods. In addition, this study used both descriptive survey research design and explanatory research design to help identify, analyze, and describe management of devolved health services, leadership style, in-service training and health-care service delivery in arid and semi-arid lands in Kenya. descriptive survey design was used to allow for description of devolution, leadership style and health care service delivery. Previous studies by Abe and Monisola (2014), Macharia et al., (2014), Opiyo (2014) and Wangari (2014) examined the relationship between devolution and service delivery and used the descriptive design. Several previous studies on decentralization and service delivery have used explanatory research design with satisfactory results (Adam et al., 2012; Alaaraj \& Ibrahim, 2014).

\subsection{Population}

The population under this study constitute the Sub-Counties in ASALs in Kenya. According to the Ministry of Planning and Devolution Report (2016), there are one hundred and thirteen (113) Sub-Counties demarcated as Arid and Semi-Arid Lands (ASAL) and distributed within 23 counties in Kenya. The Ministry further categorises the 113 Sub-Counties into Arid (36 Sub-Counties in 8 counties) and Semi-Arid (77 Sub-Counties in 15 counties)

\subsection{Sample and Sampling Technique}

A sample is a small proportion of targeted population selected. In cases where a census (a survey of the entire population) is impossible, sampling procedures provide a justified option (Kothari, 2004). In this regard sampling of the ASAL Sub-Counties was done using the Slovin's Formula (as used by Ariola, 2006). The formula is expressed as $\mathrm{n}=\mathrm{N} /\left(1+\mathrm{Ne}^{2}\right)$

Where: $\mathrm{n}$ is sample size; $\mathrm{N}$ is the population size and $\mathrm{e}$ is the tolerance error. The confidence level gives the margin of error; in this formula, it ranges from $95 \%$ to $99 \%$ implying a tolerance error of 0.05 and 0.01 respectively (Ariola, 2006). The current study used a $95 \%$ confidence level implying a 0.05 tolerance error. Therefore, using Slovin's Formula, the sample size was calculated as: $\mathrm{n}=113 /\left(1+113(0.05)^{2}\right)=88.11 \approx 89$ sub-counties.

Proportionate sampling was then used to allocate the proportion of the sample size going to each of the 23 counties. Kothari (2004) noted that proportionate sampling is used when a population from which sample is to be drawn does not constitute a homogeneous group. Proportionate sampling involves dividing the population into a series of relevant proportions which implies that the sample is likely to be representative. Sub-counties which form our population are characterized by heterogeneous groups, given that some fall in Arid Lands while others are in Semi-Arid Lands. Proportions for this study were effectively applied at county level where the number of sub-counties in each county formed the proportion of sample size going to the county. Random sampling was then applied to select sub-counties. The proportions used were computed as Proportion $(\mathrm{P})=$ Sample Size/Total population $=89 / 113=0.787611$. Respondents for this study comprised of two categories. The first category included 89 Sub County Health Managers with the second category comprising of 3 patients from each of the 89 sampled sub counties. Random sampling was used to select patients at the selected Sub county hospitals. This ensured those sampled would not be strained during the interviews. The total number of respondents was therefore calculated as 89 sub-county health managers plus 267 (3 X 89) patients which yielded a total of 356 respondents. This ensured a naturally heterogeneous but relatively homogeneous sample as recommended by Saifuddin (2009).

\subsection{Data Collection Instruments}

The data collection instruments were questionnaires and interview guides. Kothari (2004) defines a questionnaire as a document that consists of a number of questions printed or typed in a definite order on a form or set of 
forms.

\subsection{Data Collection Procedure}

In this study, primary data was collected through questionnaires and interview guides. The researcher trained four research assistants who was engaged in collecting primary data. Secondary data was collected by the researcher himself from records obtained from the respective counties and related to issues on health-care service delivery. This was done by first seeking authority from the relevant county and sub-county authorities in ASALs, Management University of Africa and National Commission for Science Technology and Innovation (NACOSTI). For purposes of collecting data in this study, the questionnaire and interview guide was administered to the relevant respondents in the institutions by research assistants and filled by the selected respondents. The filled questionnaires and interview guides were brought to the researcher for analysis.

\subsection{Validity and Reliability Tests}

The researcher carried out a pilot study to pre-test the validity and reliability of data collected using the questionnaire that was administered to 10 healthcare staff in one county within ASAL. The clarity of the instrument items was necessary so as to enhance the instrument's validity and reliability. The aim was to correct inconsistencies arising from the instruments, which ensures that they measure what is intended. The pilot data was not included in the actual study. For this study, the researcher used expert judgment to determine whether there was any ambiguity in any information and if any it was adjusted or corrected.

The reliability was tested for internal consistency using the Cronbach alpha coefficient. The rationale for internal consistency is that the individual items should all be measuring the same constructs and thus correlates positively to one another (Kipkebut, 2010). The Alpha can take any value from zero (no internal consistency) to one (complete internal consistency). Nunnally (1978) suggested that as a rule of thumb, scores in the ranges $0.5-0.6$, $0.6-0.7,0.7-0.8$, and $0.8-0.9$, should be considered to have an internal consistency that is poor, questionable, acceptable or good, respectively. Values above 0.9 represent excellent internal consistency, while values less than 0.5 are considered to be unacceptable. This study found an average alpha of 0.83 and thus the research instruments were found to be consistent.

Data collected was first checked on the level of response before actual data analysis is undertaken using IBM SPSS version 24 and Microsoft excel. Those whose level of response were found to be adequate was assigned numbers for coding into the computer. Then the data collected was subjected to qualitative and quantitative analysis. With respect to this, the quantitative data was categorized according to subject concept of the objectives of this study. The organized data was then interpreted in the light of the research problem to be addressed and used to enhance the quantitative findings.

Quantitative analysis entailed computing descriptive statistics like the frequency and percentage for the quantitative data. Measures of central tendency were also used in which case the mean and the mode were computed. At the same time, measures of dispersion were computed particularly the standard deviation. Inferential statistics were all applied on the quantitative data where correlation analysis, analysis of variance (ANOVA) and regression analysis was done. Presentation of findings shall be done using tables, pie charts, bar graphs as well as histograms for interpretation, summary and conclusions. In conducting the regression analysis, simple and multiple linear regressions analysis done in which case, the regression was done at different levels. Qualitative findings on the other hand were derived from in-depth interviews (IDIs) that were conducted with beneficiaries of health services in ASAL. Analysis was done using R-based Qualitative Data Analysis (RQDA) software and results presented in bar plots and word clouds.

\section{Results}

Results were presentated based on the two variables, that is, management of devolved health services, and healthcare service delivery. 


\subsection{Management of devolved health Services}

Table 1. Descriptive statistics for management of devolved health service

\begin{tabular}{|c|c|c|c|c|c|c|c|c|c|}
\hline Factor & $\begin{array}{l}\text { Strongly } \\
\text { disagree }\end{array}$ & Disagree & Not sure & Agree & $\begin{array}{l}\text { Strongly } \\
\text { agree }\end{array}$ & Mean & $\begin{array}{l}\text { Medi } \\
\text { an }\end{array}$ & Mode & $\begin{array}{l}\text { Standard } \\
\text { Deviation }\end{array}$ \\
\hline $\begin{array}{l}\text { a) The residents from all sub-counties } \\
\text { are engaged by the County government in } \\
\text { making health services decisions in } \\
\text { Sub-County leadership }\end{array}$ & $6.3 \%$ & $22.8 \%$ & $3.8 \%$ & $58.2 \%$ & $8.9 \%$ & 3.4 & 4.0 & 4.0 & 1.1 \\
\hline $\begin{array}{l}\text { b) My Sub-County leadership } \\
\text { considers the opinions raised by the } \\
\text { residents while implementing health } \\
\text { services decisions }\end{array}$ & $0.0 \%$ & $13.9 \%$ & $5.1 \%$ & $51.9 \%$ & $29.1 \%$ & 4.0 & 4.0 & 4.0 & 1.0 \\
\hline $\begin{array}{l}\text { c) Issues concerning health services } \\
\text { are effectively communicated to all } \\
\text { stakeholders in Sub-County leadership }\end{array}$ & $1.3 \%$ & $16.5 \%$ & $3.8 \%$ & $59.5 \%$ & $19.0 \%$ & 3.8 & 4.0 & 4.0 & 1.0 \\
\hline $\begin{array}{l}\text { d) Management of devolved } \\
\text { healthcare has enabled Sub-County } \\
\text { leadership to introduce better technologies } \\
\text { at health facilities }\end{array}$ & $7.6 \%$ & $30.4 \%$ & $13.9 \%$ & $39.2 \%$ & $8.9 \%$ & 3.1 & 3.0 & 4.0 & 1.2 \\
\hline $\begin{array}{l}\text { e) Residents are able to access health } \\
\text { services information since introduction of } \\
\text { county governments }\end{array}$ & $1.3 \%$ & $16.5 \%$ & $16.5 \%$ & $46.8 \%$ & $19.0 \%$ & 3.7 & 4.0 & 4.0 & 1.0 \\
\hline $\begin{array}{l}\text { f) Devolution has facilitated adequate } \\
\text { maintenance of health technologies } \\
\text { compared to before }\end{array}$ & $7.6 \%$ & $31.6 \%$ & $12.7 \%$ & $40.5 \%$ & $7.6 \%$ & 3.1 & 3.0 & 4.0 & 1.2 \\
\hline $\begin{array}{l}\text { g) There has been introduction of } \\
\text { more healthcare facilities at counties } \\
\text { because of devolution }\end{array}$ & $1.3 \%$ & $10.1 \%$ & $1.3 \%$ & $35.4 \%$ & $51.9 \%$ & 4.3 & 5.0 & 5.0 & 1.0 \\
\hline $\begin{array}{l}\text { h) Adequacy of health care equipment } \\
\text { at county health facilities has improved }\end{array}$ & $8.9 \%$ & $11.4 \%$ & $3.8 \%$ & $59.5 \%$ & $16.5 \%$ & 3.6 & 4.0 & 4.0 & 1.2 \\
\hline $\begin{array}{l}\text { i) Management of devolved health } \\
\text { services, has enhanced better maintenance } \\
\text { of health-care infrastructure compared to } \\
\text { before devolution }\end{array}$ & $11.4 \%$ & $22.8 \%$ & $10.1 \%$ & $40.5 \%$ & $15.2 \%$ & 3.3 & 4.0 & 4.0 & 1.3 \\
\hline $\begin{array}{l}\text { j) Management of devolved } \\
\text { healthcare has led to more health fund } \\
\text { allocated to county governments from } \\
\text { national government }\end{array}$ & $6.3 \%$ & $12.7 \%$ & $27.8 \%$ & $32.9 \%$ & $20.3 \%$ & 3.5 & 4.0 & 4.0 & 1.1 \\
\hline $\begin{array}{l}\text { k) Devolution has improved efficient } \\
\text { budget allocations to health activities } \\
\text { within my county }\end{array}$ & $16.5 \%$ & $25.3 \%$ & $11.4 \%$ & $44.3 \%$ & $2.5 \%$ & 2.9 & 3.0 & 4.0 & 1.2 \\
\hline $\begin{array}{l}\text { 1) County citizens/residents are able } \\
\text { to access healthcare at relatively lower } \\
\text { price since devolution of health services }\end{array}$ & $2.5 \%$ & $13.9 \%$ & $7.6 \%$ & $44.3 \%$ & $31.6 \%$ & 3.9 & 4.0 & 4.0 & 1.1 \\
\hline Average & $5.9 \%$ & $19.0 \%$ & $9.8 \%$ & $46.1 \%$ & $19.2 \%$ & 3.5 & 3.8 & 4.1 & 1.1 \\
\hline
\end{tabular}

As shown in Table 1, respondents strongly agreed that there has been introduction of more healthcare facilities at counties in ASAL resulting from devolution (mean $=4.3$, mode $=5.0$, median $=5.0$, standard deviation $=1.0$ ). At the same time findings revealed that sub-County leaderships have been largely considering the opinions raised by the residents while implementing health services decisions (mean $=4.0$, mode $=4.0$, median $=4.0$, standard deviation $=1.0$ ) while allowing them (citizens/residents) to access healthcare at relatively lower price since devolution of health services $($ mean $=3.9$, mode $=4.0$, median $=4.0$, standard deviation $=1.1)$. It was as well noted that issues concerning health services are at a effectively but at a moderate level communicated to all stakeholders in sub-County leadership $($ mean $=3.8$, mode $=4.0$, median $=4.0$, standard deviation $=1.0)$ with 
residents are able to access health services information since introduction of county governments (mean $=3.7$, mode $=4.0$, median $=4.0$, standard deviation $=1.0$ ).

Respondents, nonetheless, expressed reservations regarding whether management of devolved healthcare has enabled sub-County leadership to introduce better technologies at health facilities as given by an unresolved mean of 3.1 and mode of 3.0 but with high median of 4.0 and standard deviation $=1.2$. Respondents also disagreed that, devolution has facilitated adequate maintenance of health technologies compared to before (mean $=3.1$, mode $=3.0$, median $=4.0$, standard deviation $=1.2)$ as well as moderately dissenting that devolution has improved efficient budget allocations to health activities within my county (mean $=2.9$, mode $=3.0$, median $=$ 4.0 , standard deviation $=1.2$ ). Based on the average, management of devolved health services had mean of 3.5 with mode, median and standard deviation of 3.8, 4.1 and 1.1 respectively implying that respondents agreed on most of the constructs of management of devolved health services in ASAL. While devolution has brought healthcare services nearer to the residents, the county government has nonetheless not been able to adequately meet budget requirements.

\subsection{Health-Care Service Delivery}

Descriptive statistics for health-care service delivery was based on nine (9) constructs as presented in Table 2

Table 2. Descriptive statistics for health-care service delivery

\begin{tabular}{|c|c|c|c|c|c|c|c|c|c|}
\hline Factor & $\begin{array}{l}\text { Strongly } \\
\text { disagree }\end{array}$ & Disagree & Not sure & Agree & $\begin{array}{l}\text { Strongly } \\
\text { agree }\end{array}$ & $\begin{array}{l}\text { Mea } \\
\mathbf{n}\end{array}$ & $\begin{array}{l}\text { Medi } \\
\text { an }\end{array}$ & $\begin{array}{l}\text { Mod } \\
\text { e }\end{array}$ & $\begin{array}{l}\text { Standard } \\
\text { Deviation }\end{array}$ \\
\hline $\begin{array}{l}\text { a) As a result of management of } \\
\text { devolved health services, healthcare } \\
\text { facilities and services are now accessible } \\
\text { to residents. }\end{array}$ & $0.0 \%$ & $7.6 \%$ & $5.1 \%$ & $62.0 \%$ & $25.3 \%$ & 4.1 & 4.0 & 4.0 & 0.8 \\
\hline $\begin{array}{l}\text { b) In the last five years the quality of } \\
\text { the health services at county health } \\
\text { centers has greatly improved }\end{array}$ & $0.0 \%$ & $26.6 \%$ & $12.7 \%$ & $49.4 \%$ & $11.4 \%$ & 3.5 & 4.0 & 4.0 & 1.0 \\
\hline $\begin{array}{l}\text { c) Am satisfied with health services } \\
\text { provided by county health centers }\end{array}$ & $3.8 \%$ & $36.7 \%$ & $6.3 \%$ & $45.6 \%$ & $7.6 \%$ & 3.2 & 4.0 & 4.0 & 1.1 \\
\hline $\begin{array}{l}\text { d) Healthcare complaints from } \\
\text { residents have easily been handled by } \\
\text { county government compared to before }\end{array}$ & $3.8 \%$ & $31.6 \%$ & $11.4 \%$ & $45.6 \%$ & $7.6 \%$ & 3.2 & 4.0 & 4.0 & 1.1 \\
\hline $\begin{array}{l}\text { e) Am satisfied with healthcare } \\
\text { programs introduced by the county } \\
\text { government }\end{array}$ & $3.8 \%$ & $28.2 \%$ & $15.4 \%$ & $47.4 \%$ & $5.1 \%$ & 3.2 & 4.0 & 4.0 & 1.0 \\
\hline $\begin{array}{l}\text { f) Healthcare delivery has been more } \\
\text { efficient since devolution health services } \\
\text { compared to before }\end{array}$ & $6.3 \%$ & $26.6 \%$ & $17.7 \%$ & $39.2 \%$ & $10.1 \%$ & 3.2 & 3.0 & 4.0 & 1.1 \\
\hline $\begin{array}{l}\text { g) Prompt attention is always given to } \\
\text { the patient who visits county government } \\
\text { health centers or hospitals }\end{array}$ & $3.8 \%$ & $17.7 \%$ & $17.7 \%$ & $48.1 \%$ & $12.7 \%$ & 3.5 & 4.0 & 4.0 & 1.1 \\
\hline $\begin{array}{l}\text { h) Drugs are always provided to the } \\
\text { patients in the hospitals or county } \\
\text { government health centers }\end{array}$ & $6.3 \%$ & $25.3 \%$ & $13.9 \%$ & $49.4 \%$ & $5.1 \%$ & 3.2 & 4.0 & 4.0 & 1.1 \\
\hline $\begin{array}{l}\text { i) Cost of Health Care Services have } \\
\text { reduced significantly }\end{array}$ & $2.5 \%$ & $21.5 \%$ & $6.3 \%$ & $45.6 \%$ & $24.1 \%$ & 3.7 & 4.0 & 4.0 & 1.1 \\
\hline Average & $3.4 \%$ & $24.6 \%$ & $11.8 \%$ & $48.0 \%$ & $12.1 \%$ & 3.4 & 3.9 & 4.0 & 1.0 \\
\hline
\end{tabular}

Findings as presented in Table 2 shows that, management of devolved health services has greatly made health facilities and services more accessible to residents compared to before (mean $=4.1$, mode $=4.0$, median $=4.0$, standard deviation $=0.8$ ). In addition, the previous five years has recorded great improvement in the quality of 
the health services at county health centers (mean $=3.5$, mode $=4.0$, median $=4.0$, standard deviation $=1.0)$ with respondents fairly satisfied with health services provision by county health centers $($ mean $=3.2$, mode $=4.0$, median $=4.0$, standard deviation $=1.1$ ).

Based on average, mean was found to be 3.4, median 3.9, mode (4.0) and standard deviation (1.1). Findings confirmed that management of devolved health services has resulted to better healthcare facilities and with healthcare services being more accessible to residents as well as cost of health care services having reduced significantly. Despite these improvements, residents are not adequately satisfied with some health services especially on handling of healthcare complaints from residents by county government compared to before, healthcare programs introduced by the county government. Availability of drugs in health facilities was also found to a major inefficient side of management of devolved health services.

\subsection{Test for Normality and Homoscedasticity}

\subsubsection{Test for Normality}

Normality test was used to assess whether sample data had been drawn from a normally distributed population. This assessment was important since normal data is an underlying assumption in parametric testing. The test was achieved using Normal Q-Q plot and One-Sample Kolmogorov-Smirnov Test

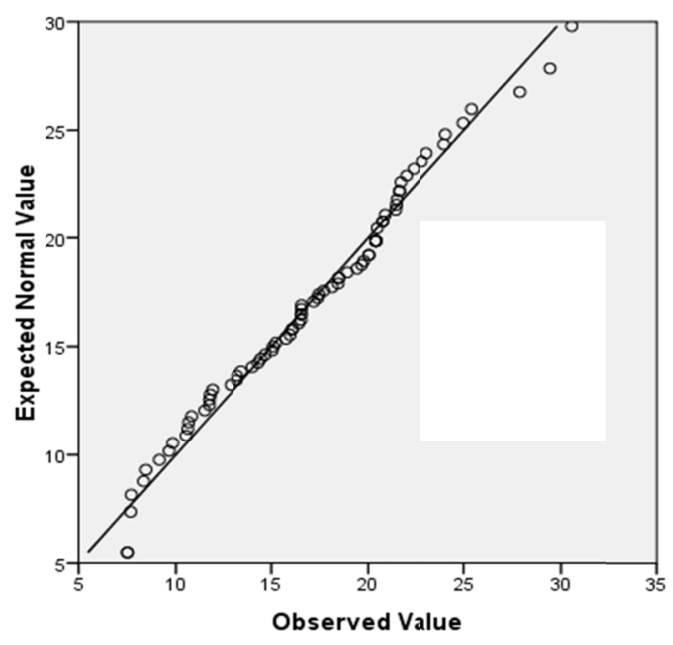

Figure 1. Normal Q-Q Plot of health-care service delivery

The output of a normal Q-Q plot was used to determine normality graphically. If the data are normally distributed, the data points will be close to the diagonal line. If the data points stray from the line in an obvious non-linear fashion, the data are not normally distributed. As shown in Figure 1, the data is normally distributed.

Table 3. One-Sample Kolmogorov-Smirnov Test

\begin{tabular}{lll}
\hline & & Health Care Service Delivery \\
\hline $\mathrm{N}$ & & 79 \\
Normal Parameters & Mean & 17.0543 \\
& Std. Deviation & 5.27971 \\
Most Extreme Differences & Absolute & 0.069 \\
& Positive & 0.064 \\
& Negative & -0.069 \\
Kolmogorov-Smirnov Z & & 0.61 \\
Asymp. Sig. (2-tailed) & & 0.85 \\
Test distribution is Normal. & & \\
\hline
\end{tabular}

The difference between the observed distribution and a perfectly normal one is checked based on a p-Value. If 
the $\mathrm{p}$-Value is less than 0.05 , the distribution is significantly different from a normal distribution and might be cause for concern. If it is 0.05 or higher, there is no significant difference from normality. As shown in Table 3 , the data for management of devolved health services was normally distributed as p-Value was greater than 0.05 for healthcare service delivery with overall p-Value using Kolmogorov-Smirnova normality index being $0.85>0.05$. Thus, the sample data for this study had been drawn from a normally distributed population. This assessment was important since normal data is an underlying assumption in parametric testing.

\subsubsection{Test for Homoscedasticity}

One of important assumptions of linear regression is that the variance of error term is constant across observations. If the error has constant variance, then the errors are said to be homoscedastic, otherwise heteroscedastic. In case of heteroscedastic errors (non-constant variance), the standard estimation methods become inefficient.

Table 4. Breusch - Pagan Test for Homoscedasticity

\begin{tabular}{lll}
\hline Breusch -Pagan Test Statistic & Degrees of Freedom & $\mathrm{p}$-Value \\
\hline 0.202 & 1 & 0.653 \\
\hline
\end{tabular}

In this study, Breusch-Pagan test (named after Trevor Breusch and Adrian Pagan) was used to test for homoscedasticity. For Breusch-Pagan test the null hypothesis assumes homoscedasticity which is stated as follows:

Null Hypothesis $\left(\mathrm{H}_{0}\right)$ : The data (residuals) is homoscedastic

Alternative Hypothesis $\left(\mathrm{H}_{1}\right)$ : The data is heteroscedastic

The decision rule is:

If $\mathrm{p}$-Value $<\alpha$; then null hypothesis is rejected.

If $\mathrm{p}$-Value $>\alpha$; then we fail to reject the null hypothesis.

Where $\alpha$ is the level of significance (alpha)

Test for homoscedasticity in this study generated a p-Value of 0.653 (Table 4) and therefore we fail to reject the null hypothesis and conclude that the data (residuals) is homoscedastic.

\subsection{Management of Devolved Health Services and Healthcare Service Delivery}

Inferential statistics were determined entailing correlation coefficient, coefficient of determination (R-Square), analysis of variance as well as regression coefficients. Test for autocorrelation was also performed

Table 5. Coefficient of Determination on the Relationship between Management of Devolved Health Services and Health Care Service Delivery

\begin{tabular}{lllll}
\hline $\mathrm{R}$ & $\mathrm{R}-\mathrm{Square}$ & Adjusted R-Square & Std. Error of the Estimate & Durbin-Watson \\
\hline 0.809 & 0.654 & 0.649 & 3.127 & 2.277 \\
\hline
\end{tabular}

Results in Table 5 show an R-Square of 0.654 with the standard error of estimate being 3.127. This implies that management of devolved health services significantly explains changes in healthcare service delivery. The researcher also tested for autocorrelation using Durbin Watson statistic which is a test for autocorrelation in the residuals from a statistical regression analysis and always between 0 and 4 . The Hypotheses for the Durbin Watson test are:

$\mathrm{H}_{0}=$ No first order autocorrelation

$\mathrm{H}_{1}=$ First order correlation exists.

(For a first order correlation, the lag is one-time unit).

A rule of thumb is that, test statistic values in the range of 1.5 to 2.5 are relatively normal. Values outside of this range could be cause for concern. Field (2009) suggests that values under 1 or more than 3 are a definite cause for concern. For the current study, Durbin Watson statistic was 2.277 which falls within the relatively-normal range and therefore there was no presence of autocorrelation in the residuals from a regression analysis. 
Table 6. Analysis of Variance on the relationship between Management of devolved health services and health care service delivery

\begin{tabular}{llllll}
\hline & Sum of Squares & $\mathrm{df}$ & Mean Square & $\mathrm{F}$ & Sig. \\
\hline Regression & 1421.302 & 1 & 1421.3 & 145.344 & .000 \\
Residual & 752.974 & 77 & 9.779 & & \\
Total & 2174.276 & 78 & & & \\
\hline
\end{tabular}

As shown in Table 6, F-Calculated $(1,77)=145.344$ which is greater than F-Critical $(1,77)=3.965$ at 2 -tail test and $95 \%$ confidence level. Results also show $p$-Value $=0.000<0.05$. This further confirms that management of devolved health services significantly influences healthcare service delivery.

Table 7. Regression coefficients on the relationship between management of devolved health services and health care service delivery

\begin{tabular}{|c|c|c|c|c|c|}
\hline & \multicolumn{2}{|c|}{ Unstandardized Coefficients } & \multirow{2}{*}{$\begin{array}{l}\text { Standardized Coefficients } \\
\text { Beta }\end{array}$} & \multirow[t]{2}{*}{$\mathrm{t}$} & \multirow[t]{2}{*}{ Sig. } \\
\hline & $\mathrm{B}$ & Std. Error & & & \\
\hline (Constant) & 2.186 & 1.283 & & 1.704 & 0.092 \\
\hline \multicolumn{6}{|c|}{ Management of devolved health } \\
\hline Services & 0.648 & 0.054 & 0.809 & 12.000 & .000 \\
\hline
\end{tabular}

Findings as shown in Table 7 express that, when management of devolved health services is held constant, healthcare service delivery will remain at 2.186. At the same time, an increase in management of devolved health services by one unit would lead to an increase in healthcare service delivery by 0.648 units with a p-Value of $0.000<0.05$. This can be summarized by the following model: $Y=\mathbf{2 . 1 8 6}+\mathbf{0 . 6 4 8 X}$

In summary, given R-Square $=0.654$ with F-Calculated $(1,77)=145.344$ which is greater than F-Critical $(1,77)$ $=3.96$ at 2 -tail test and $95 \%$ confidence level and $\mathrm{p}$-Value $=0.000<0.05$ as well as a positive elasticity $(0.654)$ the researcher did not accept the null hypothesis $\left(\mathrm{H}_{1}\right)$ and therefore concludes that there is positive and significant influence of management of devolved health services on healthcare service delivery in ASAL in Kenya.

\subsection{Qualitative Findings}

Qualitative findings were derived from in-depth interviews (IDIs) that were conducted with beneficiaries of health services in ASAL. Analysis was done using R-based Qualitative Data Analysis (RQDA) software and results presented in bar plots and word clouds. This was achieved by visual representation of text data in the form of tags and whose frequency of occurrence indicated level of prevalence as visualized by bar size, text size, text weight as well as the text color.

\subsubsection{Communities Involved in Health Care Service Delivery}

This section was intended to complement findings on leadership style by county leadership in ASAL. Bar plot of most occurring adjectives and word cloud were used to present responses on communities' involvement in health care service delivery as shown in Figures 2 and 3.

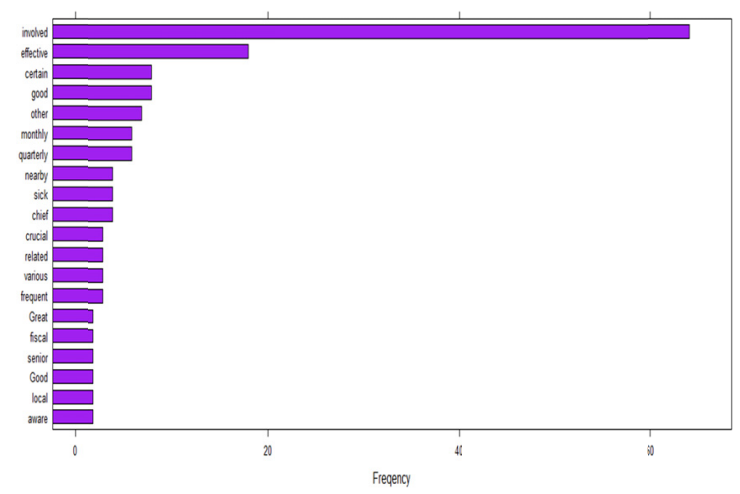

Figure 2. Bar Plot of Most Occurring Adjectives on communities involvement in health care service delivery 
Figure 2 presents the bar plot of most occurring adjectives on communities' involvement in health care service delivery. The plot indicates involvement of communities have not only been existing but has also been effective. Interviewees noted that there has been great involvement of community healthcare service delivery after devolution through communities' participation when meeting to select projects for fiscal years and establishment of community units where facility management committee and health workers normally hold meeting on monthly or quarterly bases. It was also revealed that, this involvement has been very effective because it is made through facility management committee hospital board as well as frequent community meeting in the community units

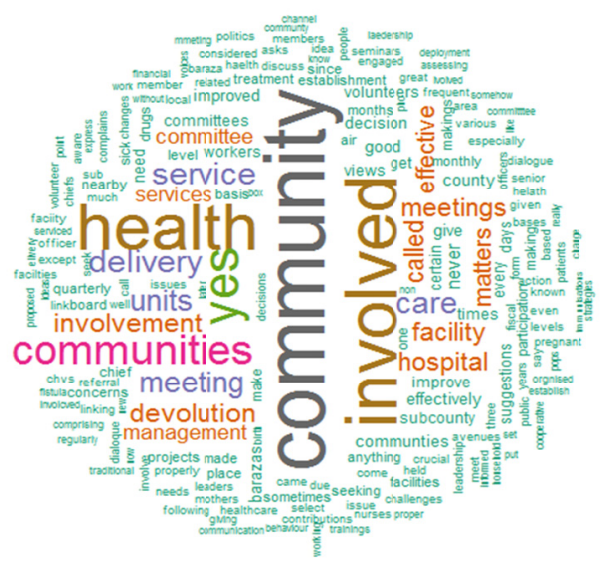

Figure 3. Word Cloud on communities involvement in health care service delivery

Figure 3 illustrates word cloud on communities' involvement in health care service delivery and confirms findings in Figure 2 that communities are involved in healthcare service delivery in arid and semi-arid areas. Other most noticeable texts include effective, committee, involvement and meeting implying that communities are to a great extent involved in healthcare service delivery

\subsubsection{Devolution in Health Services and Improvement in Healthcare Service Delivery}

This section presents contribution of devolution in health services in healthcare service delivery. Figure 4 addresses this by establishing whether management of devolved health services has led to improvement in healthcare service delivery in respondent's county. Word cloud on aspects of healthcare service delivery that have improved as a result of management of devolved health services is also presented in Figure 5.

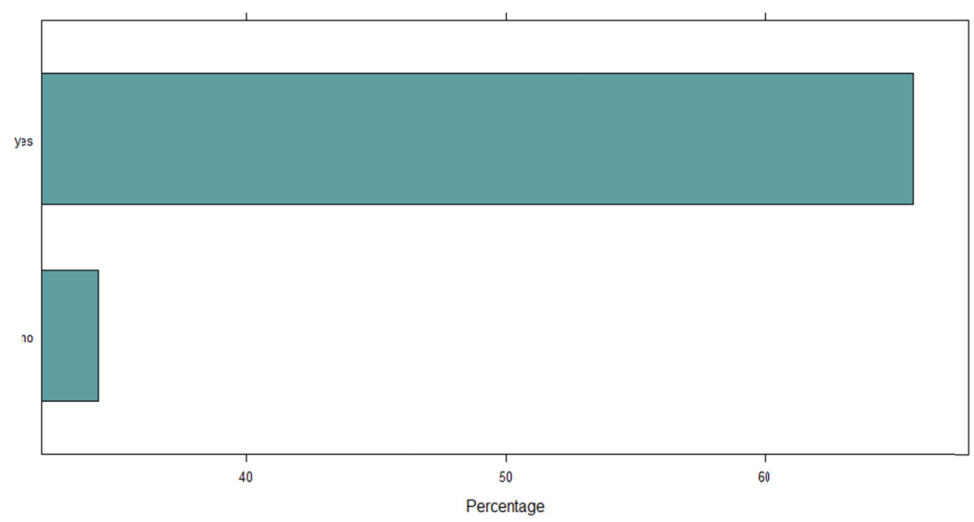

Figure 4. Whether Management of devolved health services has led to improvement in healthcare service delivery in respondent's county

As shown in Figure 4, over 70 percent of respondents indicated their satisfaction on management of devolved health services expressing that the devolved governance has led to improvement in healthicare service delivery in ASAL. Less than 30 percent were however of different opinion and negated contribution of management of 
devolved health service in improving healthcare service delivery.

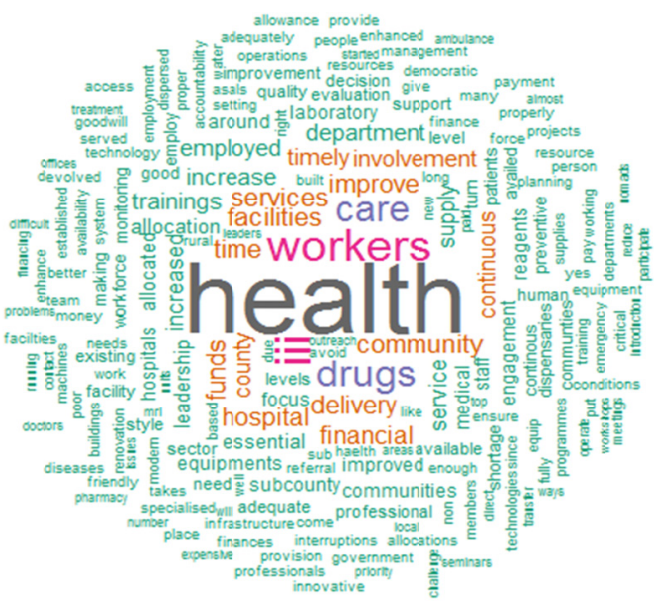

Figure 5. Word cloud on aspects of healthcare service delivery that have improved as a result of management of devolved health services

Word cloud on aspects of healthcare service delivery that have improved as a result of management of devolved health services (Figure 5) has delineated timely and continuous workers and community involvement in healthcare service delivery as key aspects that have improved as a result of devolution. Funds to counties and improved health facilities were also noticeable aspects.

\section{Findings and Discussion}

\subsection{Management of Devolved Health Services}

This study found that, there has been introduction of more healthcare facilities at counties in ASAL resulting from devolution $($ mean $=4.3$, mode $=5.0$, median $=5.0$, standard deviation $=1.0)$. At the same time findings revealed that sub-County leaderships have been largely considering the opinions raised by the residents while implementing health services decisions ( mean $=4.0$, mode $=4.0$, median $=4.0$, standard deviation $=1.0$ ) while allowing them (citizens/residents) to access healthcare at relatively lower price since devolution of health services $($ mean $=3.9$, mode $=4.0$, median $=4.0$, standard deviation $=1.1$ ). The findings are in line with Fiscal Decentralization Theory that allocative efficiency of the decentralized provision of most public services is higher than that of the centralized provision because lower levels of government can improve the well-being of residents through a more comprehensive satisfaction of their individual needs (preference-matching argument). There is high possibility to increase the allocative and productive efficiency of public goods provision under devolution (Martinez-Vazquez and McNab, 2003, Oates, 1999, Thiessen, 2003). The productive efficiency can also be higher under decentralization because subnational authorities, which have better knowledge of citizens' needs and experience in providing respective public goods, can produce such goods at lower cost.

This is also confirming that, devolution grants the devolved governments the capacity to develop policies that are better tailored to the economic and social conditions of their areas, encouraging policy divergence through the introduction of "local solutions to local problems" (Mackinnon, 2015). Moreover, Mackinnon (2015) indicated that devolution creates logic of inter-territorial comparison and competition, potentially resulting in policy learning and transfer as the different administrations monitor developments elsewhere, adopting successful or popular policies from other jurisdictions. However, Yusoff, Sarjoon, Awang, and Efendi (2016) contend that in devolution, powers are transferred to autonomous units governed independently and separately without the direct control of central government. Devolution provides a unique opportunity to strengthen primary healthcare service delivery. With counties now responsible for delivering primary healthcare services there is hope that some of the chronically persisting weaknesses to make the existing facilities operational will be addressed (Government of Kenya, 2014).

Despite this, this study has established that management of devolved health services has failed to improve efficient budget allocations to health activities in ASAL as given by an unresolved mean of 3.1 and mode of 3.0 but with high median of 4.0 and standard deviation $=1.2$. Respondents also disagreed that, devolution has facilitated adequate maintenance of health technologies compared to before $($ mean $=3.1$, mode $=3.0$, median $=$ 
4.0, standard deviation $=1.2$ ) as well as moderately dissenting that devolution has improved efficient budget allocations to health activities within my county $($ mean $=2.9$, mode $=3.0$, median $=4.0$, standard deviation $=$ 1.2). This could be explained by the fact that Kenya is such that the country still lacks a comprehensive health financing strategy (Ravishankar et al, 2013). Briscombe et al., (2010) also adds that the allocation of health sector financial resources remains highly centralized and opaque, relying primarily on previous years' budget allocations rather than on health needs indicators. The Health Policy Initiative's research revealed that the allocation of health sector funds in Kenya has not accounted for differences in health achievement, access, and provision costs across the regions, provinces, and districts.

According to a study by Jongudomsuk and Srisasalux (2012), health-care decentralization cannot be implemented effectively without the support of the central government. In Serbia, Milicevic, Vasic, and Edwards (2015) reported that bottlenecks related to distribution of human resources and financing did adversely influence both the implementation of health care projects and provision of health care services by municipal governments. Thus, devolution as a mode of decentralization is accompanied by sound financial resource base of local governments, full autonomy to local governments in human resource management matters, regular capacity building of local officials, performance-based incentive structures, and participatory governance.

\subsection{Healthcare Service Delivery}

Findings in this study has revealed that management of devolved health services, healthcare has to a great extent made health facilities and services more accessible to residents compared to before with the previous five years recording great improvement in the quality of the health services at county health centers. These findings conform to the central goals of management of devolved healthcare services to improve access, equity, quality, efficiency and/or sustainability (WB \& CMI, 2012). Additionally, Medical Services (2010) suggested that for county governments to have successful health care system the leaders must understand the nature and implications of change, have the ability to develop effective strategies that account for change, and the will as well as the ability to actively manage the momentum of the devolution (Nzinga et al., 2013).

However, this study found that healthcare service provision in ASAL are still very poor, particularly for women and children, with high maternal, infant and child mortality, high levels of acute malnutrition, and low immunisation coverage. Poor water, sanitation and waste management facilities are also a major cause of ill-health, particularly in unplanned urban areas. The health service infrastructure is particularly poor, with few and scattered health facilities staffed by inadequate numbers of personnel. Distances to referral facilities may be much longer, on poorer roads, than in other parts of the country. Healthcare provision in ASAL could also be repressed by inadequate finance allocation, similar as Wei-qing and Shi (2010) findings that found negative effect of fiscal decentralization on public service provision in the highest in Central and West China, and the lowest in Northeast China.

\subsection{Influence of Management of Devolved Health Services on Healthcare Service Delivery in ASAL}

Results on the influence of management of devolved health services on healthcare service delivery in ASAL generated an R-Square of 0.654 with F-Calculated $(1,77)$ being 145.344 which is greater than F-Critical $(1,77)$ $=3.96$ at 2 -tail test and $95 \%$ confidence level and $\mathrm{p}$-Value $=0.000<0.05$ as well as a positive elasticity $(0.654)$. This steered to a conclusion that there is positive and significant influence of management of devolved health services on healthcare service delivery in ASAL in Kenya. These findings are consistent with those of Wei-qing and Shi (2010) who observed that devolution tended to encourage governments to allocate fiscal expenditure in infrastructure, to attract outside capital to develop local economy, but in the same time, reduced provision of public services, such as education.

Wangari (2014) also argues that devolution has both an explicit and implicit motivation of improving service delivery for two reasons; first the basic services which the state is responsible for are systematically failing. Secondly, improving service delivery through decentralization is important because these services are consumed locally. Moreover, Ghuman and Singh (2013) while analyzing the impact of devolution on public service delivery summarized that devolution as a mode of decentralization is accompanied by sound financial resource base of local governments, full autonomy to local governments in human resource management matters, regular capacity building of local officials, performance-based incentive structures, and participatory governance

\section{Conclusion and Recommendations}

Given the findings, the researcher did not accept the null hypothesis $\left(\mathrm{HO}_{1}\right)$ and therefore concludes that there is positive and significant influence of management of devolved health services on healthcare service delivery in ASAL in Kenya. The main contributor to this relationship is the fact that leaderships have been largely 
considering the opinions raised by the residents while implementing health services decisions. At the same time, devolution grants the devolved governments the capacity to develop policies that are better tailored to the economic and social conditions of their areas, encouraging policy divergence through the introduction of "local solutions to local problems". Therefore, devolution as a mode of decentralization is accompanied by sound financial resource base of local governments, full autonomy to local governments in human resource management matters, regular capacity building of local officials, performance-based incentive structures, and participatory governance.

Therefore, county leaders and in particular those in health docket should allow improvement of interpersonal relationship between the health workers and the management team to ensure increased productivity. In addition, there should be a free flow of information to ensure cohesion. Moreover, the staff should be involved in the process of decision making to ensure strict compliance. Leaders shouldn't just trust on their own decisions. This should also be complemented by health management team having the welfare of the workers at heart besides creating a work environment that will enhance workers participation in the delivery of healthcare services. Over and above, subordinates in the department of health should be adequately educated about the need for harmony with them and their leaders in the work place for the mutual benefit of both parties. This calls for improved communication. The flow of communication from top hierarchy downwards should be smooth in order to avoid unnecessary misinformation which might result into damaging effects on an organization's output.

\section{Acknowledgments}

My sincere gratitude goes to my family and friends for the support they accorded me in my study. My special thanks go to my Ph.D. classmate Mohamud Gedi for his constant encouragement not to give up. I also express earnest appreciation to my supervisors Dr. Shadrack Jirma and Professor Elijah Siringi because they have assisted me in providing direction and guidance. My special thanks also go to the entire teaching and non-teaching staff in the School of Management and Leadership whose contribution and support has helped me to reach this far in my studies. God bless you All.

\section{References}

Abe, T., \& Monisola, O. J. (2014). Citizen Participation and Service Delivery at the Local Government County Government Level: A Case of Ise/Orun Local Government County Government in Ekiti State, Nigeria. Journal of Law, Policy and Globalization, 27, 102-110.

Adam, R, Bays, P. M., \& Husain, M., (2012). Rapid decision-making under risk. Cognitive Neuroscience, 3(1), $52-61$

Ansari, U., Cockcroft, A., Omer, K., Ansari, N. D., Khan, A., Chaudhry, U. U., \& Andersson, N. (2011). Devolution and public perceptions and experience of health services in Pakistan: linked cross sectional surveys in 2002 and 2004. BMC Health Services Research, 11, 2-4.

Ariola, M. M. (2006). Principles and Methods of Research. Rex Bookstore Inc., Sampaloc., Ed. Manila: Rex Book Store.

Batley, R. (2004). The politics of service delivery reform development and change. The Journal of Global Health Care Systems, 35(1), 23-34.

Briscombe, B., Suneeta S., And Margaret S., (2010). Improving Resource Allocation in Kenya's Public Health Sector. Washington, DC: Futures Group, Health Policy Initiative, Task Order 1.

Government of Kenya. (2014). Options for Kenya's Health Financing Systems. A Policy Brief, Nairobi: Ministry of Health.

Jongudomsuk, P., \& Srisasalux, J. (2012). A decade of health-care decentralization in Thailand: what lessons can be drawn? WHO South-East Asia Journal of Public Health 2012, 1(3):347-356.

Jooste, C., \& Fourie, B. (2009). The role of strategic leadership in effective strategy implementation

Kothari. (2012). Research Methodology. Methods and Techniques.

Lobao, L., Martin, R., \& Rodrigeuz-Pose, A. (2009). Editorial:rescaling the state new modes of institutional-territorial organisation Cambridge Journal of Regions, Economies and Societies, 2, 3-12.

Lowe, G. (2012). How employee engagement matters for hospital performance. Healthcare Quarterly, 15(2), 29-40. https://doi:10.12927/hcq.2012.22915

Martinez-Vazquez, J., \& McNab, R. (2003). Fiscal decentralization and economic growth World Development, 31(9), 1597-1616 
Milicevic, M. S., Vasic, M., \& Edwards, M. (2015). Mapping the governance of human resources for health in Serbia. Health Policy, 119(12), 1613-1620: http://www.sciencedirect.com/science/article/pii/S0168851015002201.

Mongkol, K. (2011). The Critical Review of New Public Management Model and its Criticisms. Research Journal of Business Management, 5(1), 35-43.

Murkomen, O. K. (2012). Devolution and the Health System in Kenya. Strategic Thinkers and Actors Consultants Ltd., Nairobi.

Nannyonjo, J., \& Oko, N. (2013). Decentralization, Local Government Capacity and Efficiency of Health Service Delivery in Uganda. Journal of African Development, 15(1), 125-158. Retrieved from http://www.jadafea.com/wpcontent/uploads/2014/07/JAD_vol15_ch6.pdf

Nuguid, N. A. (2011). Devolution. How will the family planning program be affected when local governments get greater autonomy? Integration, (35), 26-27.

Nunnally, J. C. (1978). Psychometric theory (2nd ed.). New York: McGraw-Hill.

Nzinga. J, Lairumbi. P., \& Mike, A. (2013). Documenting the experiences of health workers expected to implement guidelines during an intervention study in Kenyan hospitals. Implementation Sci., 4(44).

Olatona, J. B., \& Olomola, P. A. (2015). Analysis of Fiscal Decentralization and Public Service Delivery in Nigeria. Journal of Economics and Sustainable Development, 6(9).

Saifuddin, A. (2009). Methods in Sample Surveys. The Johns Hopkins University and Saifuddin Ahmed.

Shiraz, S., Imran, N., Asaad, N., Aysha. Z., Zafar, F. \& Ambreen, K. (2013). Experience of devolution in district health system of Pakistan: Perspectives regarding needed reforms. Journal of Pakistan Medical Association, 62, 68-78.

Sihanya, B., (2013). Presidentialism and Administrative Bureaucracy: 1963-2013. Innovative Lawyering \& Sihanya Mentoring, Nairobi \& Siaya.

The World Bank. (2012). World Bank Fiscal Decentralisation Knowledge Programme.

Wangari, T. M. (2014). Factors Influencing Citizens' satisfaction With Service Delivery: A Case of Murang'a County, Kenya. Unpublished MSc Project, Nairobi: The University of Nairobi.

Woods, K. J. (2004). Political devolution and the health services in Great Britain. International Journal of Health Services: Planning, Administration, Evaluation, 34(2), 323-339.

Yusoff, M. A., Sarjoon, A., Awang, A., \& Efendi, D. (2016). Conceptualizing Decentralization and its Dimensions. International Business Management, 10(6), 692-701.

\section{Copyrights}

Copyright for this article is retained by the author(s), with first publication rights granted to the journal.

This is an open-access article distributed under the terms and conditions of the Creative Commons Attribution license (http://creativecommons.org/licenses/by/4.0/). 